\title{
Laparoscopic Management of Complicated Appendicitis. Is It Justified?
}

\author{
Emad Abdellatif Daoud, MD, MRCS; Shawki M.K Sharouda, MD; \\ Rania El-Ahmady, MD.
}

\author{
Department of General surgery, Ain Shams University, Cairo, Egypt.
}

Background: Complicated appendicitis is associated with a significant risk of postoperative morbidity, making the value of the laparoscopy as the first choice in the management of complicated appendicitis controversial. The objective was to study the safety and effectiveness of laparoscopy in the management of complicated appendicitis.

Patients and methods: From June 2010 to September 2014, 82 consecutive patients who underwent laparoscopic appendectomy for complicated appendicitis in 2 private hospitals in Jeddah and Ain Shams University Hospital were evaluated in a retrospective way. Complicated appendicitis was defined as perforation with a purulent peritoneal collection, abscess formation, or generalized peritonitis. The outcomes, including operative time, conversion rate, mean hospital stay, and postoperative complications were chosen to evaluate the procedure.

Conclusion: Our study demonstrated that management of complicated appendicitis laparoscopically is feasible, safe and can offer a low incidence of infectious complications, less post-operative pain, and rapid recovery.

Key words: Appendicitis, complicated appendicitis, laparoscopic appendectomy.

\section{Introduction:}

Appendicitis is the most common cause of an acute surgical abdomen, and despite advances in early diagnosis, it still shows non-negligible morbidity (10\%) and mortality (1-5\%) rates. $^{1}$ Complicated appendicitis comprises $20 \%$ to $30 \%$ of all cases of appendicitis. $^{2,3}$ It has been associated with a significant risk of postoperative septic complications, including wound infections and intra-abdominal abscess formation. ${ }^{4,5}$ Laparoscopic appendectomy when compared with open appendectomy needs higher technical demand, longer operative time and is associated with higher incidence of intraabdominal collections. ${ }^{6,7}$ While some studies concluded that laparoscopic appendectomy was superior to open appendectomy in terms of a faster recovery, improved wound healing, and earlier resumption of diet, other studies found no such benefits, or even favored conventional appendectomy. 8,9 Conversely, several trials 10,11 have found a statistically significant reduction in early postoperative complications with the laparoscopic approach to the point that it has actually been proposed as the method of choice for complicated appendicitis. The aim of this work is to justify the laparoscopic management in complicated appendicitis.

\section{Methods:}

Complicated appendicitis refers to severely inflamed, gangrenous and/or perforated appendix, which may lead to abscess formation and degrees of local or diffuse peritonitis. A retrospective analysis was performed after approval by the scientific committee. The medical records of 82 adult patients with complicated appendicitis underwent laparoscopic appendectomy in 2 private hospitals in Jeddah and Ain Shams University Hospital from June 2010 to September 2014 were reviewed regarding patient demographic data, mean operative time, conversion rate, mean hospital 
stay, postoperative abdominal and wound infections, mean time of flatus passage, return of oral intake, and late obstructive complications. 82 patients were included in the study (55 males and 27 females) and the patient's age ranged from 15 to 64 years old. Written consent were taken from all patients after giving detailed information about the operation, its complications and possibility of conversion to open procedure. After induction of general anesthesia and the insertion of a urinary catheter, low-pressure pneumoperitoneum was induced by the use of Veress needle. A three Trocars technique was used to perform the procedure. First, $10 \mathrm{~mm}$ trocar was inserted in the umbilicus and second one $10 \mathrm{~mm}$ was inserted in midway between umbilicus and xiphoid process and finally a $5 \mathrm{~mm}$ trocar was inserted in the suprapubic area. The patient was positioned in the Trendelenburg position with a mild left tilt, to facilitate the exposure of the right lower quadrant. The mesoappendix was divided by using a harmonic scalpel. The appendicular stump closure was performed by applying an endo-loop on healthy tissue next to the cecal wall and the other one around the appendix base. After section of the appendix, the extraverted appendicular mucosa was coagulated. The laparoscopic knot was the alternative technique used in difficult cases. Then, the appendix was removed from the abdominal cavity in an endo-bag and sent for histopathological study to confirm the diagnosis of complicated appendicitis. The abdominal cavity was judiciously irrigated with warm saline solution and a suction drain was inserted into the pelvis under direct visualization. Analgesics were given regularly during the hospital stay, and a clear liquid diet was allowed after the passage of flatus with gradual advancement according to patient tolerance. Antibiotic administration in the form of third generation cephalosporin and Metronidazole was given for 5 days in most patients and for 7 days in few patients. Peri-operative complications were defined as bleeding, iatrogenic injury, small bowel obstruction and enteric leak. The patients were followed up for 6 months to 1 year postoperatively.

\section{Results:}

82 patients, 55 males, and 27 females with mean age 29.16 years (range 15 to 64 years), were diagnosed as complicated appendicitis. Table (1) summarizes patients demographic data, mean operative time, conversion rate, mean hospital stay, post-operative wound infection and intra-abdominal abscess. Conversion to open appendectomy was needed in 7 patients $(8.53 \%)$ who exhibited major technical difficulties mainly due to multiple adhesions in the area. Mean operative time for the whole series was 86.83 minutes (range, 68 to 99 minutes) and mean hospital stay was 3.2 days (range 2 to 5 days). A clear liquid diet was given after passage of flatus while the mean time of flatus passage was 26.5 hours (range, 19 to 31 hours). We had one case of late intestinal obstruction after 5 months, which was treated conservatively. There were five cases of intra-abdominal infection, which were treated conservatively with a form of combined course of antibiotics for 7-10 days, two cases of them needed an ultrasound guided aspiration and drainage while four cases had a post-operative wound infection.

\section{Discussion:}

Complicated appendicitis is associated with a high risk of post-operative complications and has been considered a relative contraindication for laparoscopy. ${ }^{12,13}$ Early reports have shown an increase in intra-abdominal abscess post-operative for perforated appendicitis using the laparoscopic technique due to an establishment of pneumoperitoneum in a septic environment. Surgical learning curve issues and increased manipulation of the appendix have also been implicated. ${ }^{14,15}$ However, this concept has been changed in some studies and shows no difference between laparoscopic and open approaches regarding intraabdominal or wound infection in complicated appendicitis. ${ }^{16}$

Several meta-analyses and comparative studies have shown that it still had the 


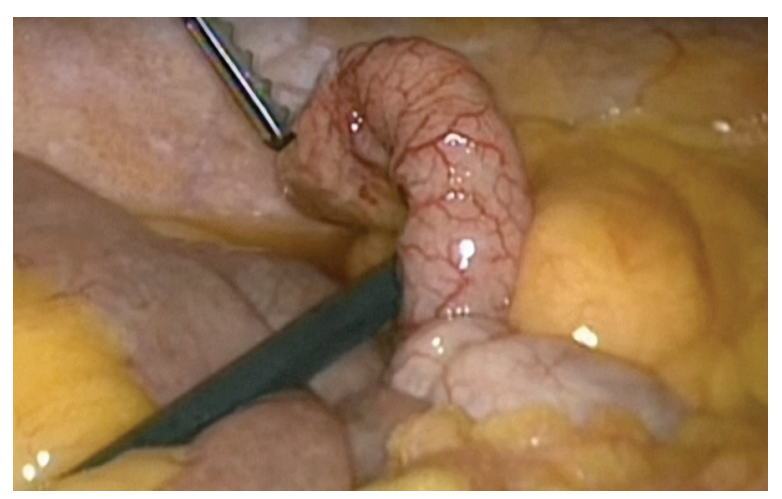

Figure (1): Shows complicated appendicitis with peritoneal collection.

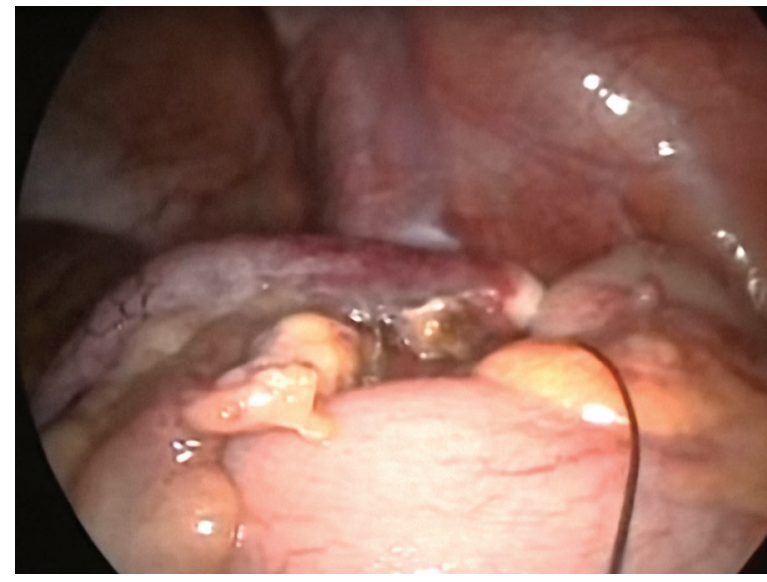

Figure (3): Shows end loop at the appendicular base.

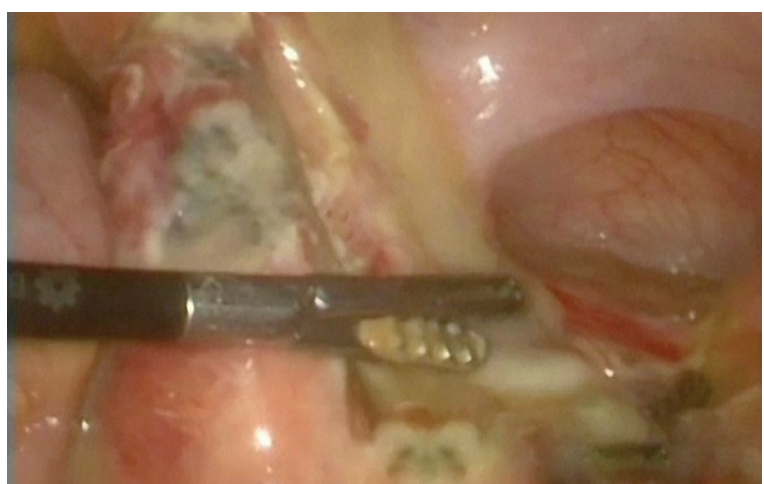

Figure (2): Shows perforated appendicitis with appendicular abscess.

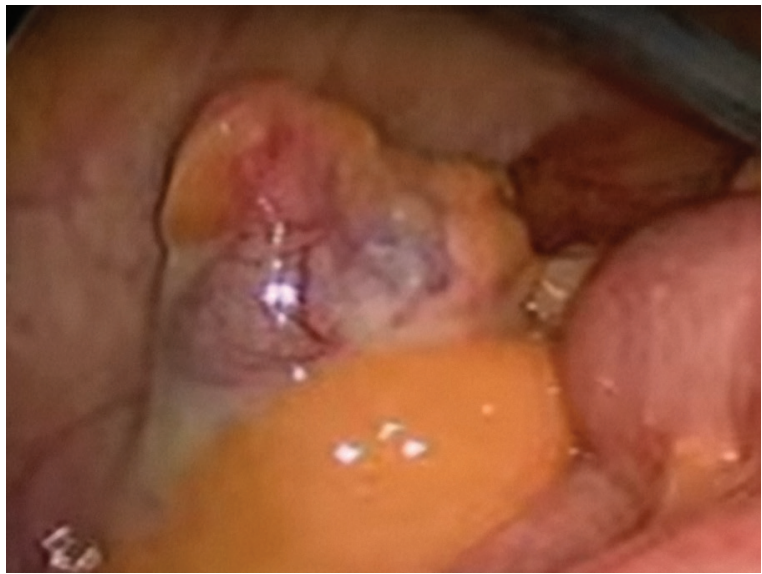

Figure (4): Severely inflamed appendix with early mass formation.

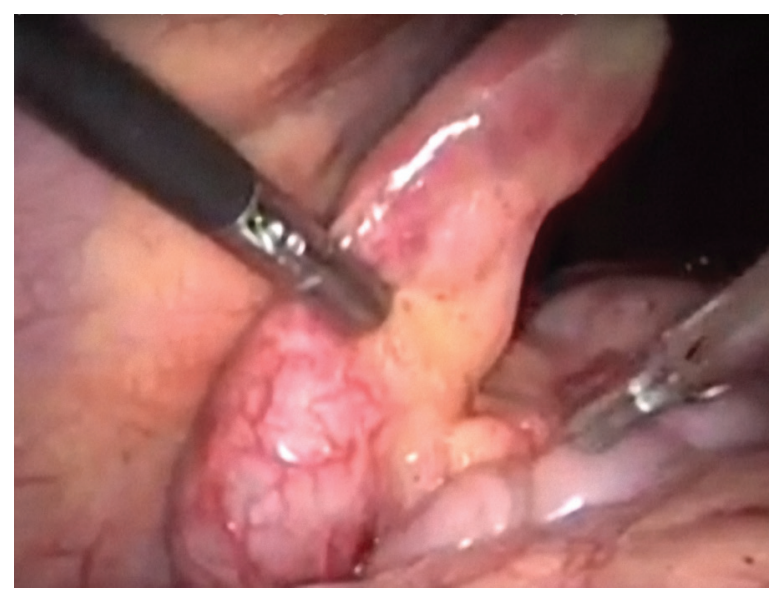

Figure (5): Shows severely inflamed appendix with gangrenous tip.

traditional advantages of the minimally invasive approach over open appendectomy in terms of reduced postoperative pain, shorter convalescence period, postoperative rapid recovery, shorter hospital stay, fewer wound infections, and fewer chest complications. ${ }^{17-19}$ All these advantages attributed to the magnification offered by the laparoscopic view, the availability of inspection of the entire peritoneal cavity, the minimal manipulation of the peritoneal cavity contents and the appendix, ability to gain access to irrigate thoroughly every intraperitoneal space contributes to the advantage of the minimally invasive approach over open surgery. ${ }^{20-23}$ 
Table (1): The demographic features of the patients of laparoscopic complicated appendicitis.

\begin{tabular}{|c|c|c|c|c|}
\hline & $\begin{array}{c}\text { Total } \\
\text { number }\end{array}$ & $\begin{array}{c}\text { Severely } \\
\text { inflamed } \\
\text { appendix with } \\
\text { early mass } \\
\text { formation }\end{array}$ & $\begin{array}{c}\text { Gangrenous } \\
\text { or perforated } \\
\text { appendix } \\
\text { with localized } \\
\text { peritonitis }\end{array}$ & $\begin{array}{c}\text { Generalized } \\
\text { peritonitis }\end{array}$ \\
\hline Number of patients & 82 & $46(56.09) \%$ & $22(26.82) \%$ & $14(17.07) \%$ \\
\hline Mean age in years & 29.16 & 28.5 & 31.5 & 27.5 \\
\hline $\begin{array}{l}\text { Sex: } \\
\\
\text { Male } \\
\text { Female } \\
\end{array}$ & $\begin{array}{l}55 \\
27 \\
\end{array}$ & $\begin{array}{l}19 \\
12 \\
\end{array}$ & $\begin{array}{l}19 \\
9 \\
\end{array}$ & $\begin{array}{l}17 \\
6 \\
\end{array}$ \\
\hline $\begin{array}{l}\text { Mean operative time (in } \\
\text { minutes) }\end{array}$ & 86.83 & 82.5 & 87.5 & 90.5 \\
\hline Rate of conversion & 7 & 1 & 2 & 4 \\
\hline $\begin{array}{l}\text { Mean time for passage of flatus } \\
\text { in hours }\end{array}$ & 26.5 & 23.8 & 27.1 & 28.6 \\
\hline Mean time hospital stay in days & 3.2 & 2.8 & 3 & 3.8 \\
\hline Intra-abdominal infection & 5 & 1 & 2 & 2 \\
\hline Postoperative wound infection & 4 & 0 & 2 & 2 \\
\hline
\end{tabular}

Our series demonstrates results consistent with the latter, while our operating strategy includes:

- Low-pressure pneumoperitoneum.

- The suction of the inflammatory peritoneal exudation was done as the first step.

- Minimal manipulation of the appendix.

- Judicious lavage of the peritoneal cavity, including the sub-diaphragmatic spaces and pelvis, which can be successfully accomplished by the various changes of patient's position.

- Use of a plastic bag for the extraction of the appendix, a maneuver that prevents peritoneal soiling and umbilical wound infection.

- Use of suction drain under direct visualization.

This finding indicates that the laparoscopic approach achieves similar results regardless of the type of complicated appendicitis. Intraabdominal abscess and wound infections were used to validate the safety and effectiveness of laparoscopy in the management of complicated acute appendicitis. A recent meta-analysis compiled 11 studies ${ }^{24-26}$ had shown that of the 2,175 operated patients with complicated acute appendicitis, 92 (4.2\%) had wound infection, which is similar to our series as it was $4.87 \%$. However, the infection rate was higher in open appendectomy in many series up to $24 \%{ }^{27-29}$ This may be due to inability to avoid contact of the abdominal incision with both the appendix and infected fluid. The same results were demonstrated in other studies where the frequency of intra-abdominal infection was 5.9\% (63 patients from 1059 patients) ${ }^{30-33}$ while the frequency of intra-abdominal infection in our series was 5 patients $(6.097 \%)$. The need of conversion to laparotomy in the management of complicated appendicitis is variable in its frequency and can reach up to $10 \% .{ }^{34} \mathrm{Among}$ the assigned factors are adhesions, localized perforation, and diffuse peritonitis, necrosis of the appendix base, retro-cecal position, bleeding and inability to identify the organs, appendicular tumor and iatrogenic injury. ${ }^{32}$ In our series, the conversion was necessary in 7 patients $(8.53 \%)$ due to some technical difficulties.

Though it has not been the object of this study, a recent meta-analysis by Merkids et $\mathrm{al}^{5}$ found no difference in operative time 
between the laparoscopy and laparotomy approaches. In this series, the mean operative time of 86.83 minutes was accepted when compared with other international studies which had an average of 80.3 minutes. ${ }^{31-34} \mathrm{It}$ is well known that laparoscopy is associated with lower postoperative adhesions and, therefore, lower rates of mechanical bowel obstructions that were what shown in our series $(1.21 \%)$ in comparison to other series which had an average of $1 \% .{ }^{35}$

\section{Conclusion:}

Our series demonstrates the justified laparoscopic approach in perforated appendicitis. Postoperative septic complications were minimal with less postoperative pain, rapid recovery, better cosmetic appearance and the convalescence were excellent. We recommend that laparoscopic appendectomy should be an initial choice for all patients with complicated appendicitis.

\section{Reference:}

1- Korndorffer JR, Fellinger E, Reed W: SAGES guideline for laparoscopic appendectomy. Surg Endosc 2010; 24(4): 757-761.

2- Paterson HM, Qadan M, de Luca SM, et al: Changing trends in surgery for acute appendicitis. Br J Surg 2008; 95(3): 363-368.

3- Schick KS, Huttl TP, Fertmann JM. Et al: A critical analysis of laparoscopic appendectomy: How experience with 1,400 appendectomies allowed innovative treatment to become standard in a university hospital. World J Surg 2008; 32(7): 1406-1413.

4- Bittner R: Laparoscopic surgery-15 years after clinical introduction. World Surg 2006; 30(7): 1190-1203.

5- Markides G, Subar D, Riyad K: Laparoscopic versus open appendectomy in adults with complicated appendicitis: Systematic review and meta-analysis. World J Surg 2010; 34(9): 2026-2040.

6- Katsuno G, Nagakari K, Yoshikawa S, et al: Laparoscopic appendectomy for complicated appendicitis: A comparison with open appendectomy. World J Surg 2009; 33(2): 208-214.

7- Lin HF, Wu JM, Tseng LM, et al: Laparoscopic versus open appendectomy for perforated appendicitis. J Gastrointest Surg
2006; 10(6): 906-910.

8- Ball CG, Kortbeek JB, Kirkpatrick AW, et al: Laparoscopic appendectomy for complicated appendicitis: An evaluation of postoperative factors. Surg Endosc 2004; 18(6): 969-973.

9- Katkhouda N, Mason RJ, Towfigh S: Laparoscopic versus open appendectomy: A prospective, randomized, double-blind study. Adv Surg 2006; 40: 1-19.

10- Bennett J, Boddy A, Rhodes M: Choice of approach for appendicectomy: A metaanalysis of open versus laparoscopic appendicectomy. Surg Laparosc Endosc Percutan Tech 2007; 17: 245-255.

11- Wei B, Qi CL, Chen TF, et al: Laparoscopic versus open appendectomy for acute appendicitis: A meta-analysis. Surg Endosc 2011; 25: 1199-1208.

12- Ignacio RC, Burke $\mathrm{R}$, Spencer $\mathrm{D}$, et al. Laparoscopic versus open appendectomy: What is the real difference? Results of a prospective randomized double-blinded trial. Surg Endosc 2004; 18: 334-337.

13- Kaplan M, Salman B, Yilmaz TU, et al: A quality of life comparison of laparoscopic and open approaches in acute appendicitis: A randomized prospective study. Acta Chir Belg 2009; 109: 356-363.

14- Moirangthem GS, Arunkumar C, Marak $\mathrm{AB}$, et al: A comparative study between laparoscopic versus open appendectomy. JMS 2008; 22: 58-62.

15- Ricca R, Schneider JJ, Brar H, et al: Laparoscopic appendectomy in patients with a body mass index of 25 or greater: Results of a double blind, prospective, randomized trial. JSLS. 2007; 11: 54-58.

16- Tzovaras G, Liakou P, Baloyiannis I, et al: Laparoscopic appendectomy: Differences between male and female patients with suspected acute appendicitis. World J Surg 2007; 31: 409-413.

17- Reshef A, Hull TL, Kiran RP: Risk of adhesive obstruction after colorectal surgery: The benefits of the minimally invasive approach may extend well beyond the perioperative period, Surg Endosc 2013; 27 : 1717-1720.

18- Kehagias I, Karamanakos SN, Panagiotopoulos $\mathrm{S}$, et al: Laparoscopic versus open appendectomy: Which way to go? World $J$ Gastroenterol 2008; 14: 4909-4914.

19- Gupta R, Sample C, Bamehriz F, et al: Infectious complications following laparoscopic appendectomy. Can J Surg 
2006; 49: 397-400.

20- Brümmer S, Sohr D, Gastmeier P: Intraabdominal abscesses and laparoscopic versus open appendectomies. Infect Control Hosp Epidemiol 2009; 30: 713-715.

21- Pokala N, Sadhasivam, S, Kiran, RP, et al: Complicated appendicitis is the laparoscopic approach appropriate? A comparative study with the open approach: Outcome in a community hospital setting. Am Surg 2007; 73: 737-741.

22- Li X, Zhang J, Sang L, et al: Laparoscopic versus conventional appendectomy a metaanalysis of randomized controlled trials. BMC Gastroenterol 2010; 10: 129-133.

23- Nakhamiyayev V, Galldin L, Chiarello $\mathrm{M}$, et al: Laparoscopic appendectomy is the preferred approach for appendicitis: A retrospective review of two practice patterns. Surg Endosc 2010; 24: 859-864.

24- Fukami Y, Hasegawa H, Sakamoto T, et al: Value of laparoscopic appendectomy in perforated appendicitis. World J Surg 2007; 31: 93-9711.

25- Mason RJ, Moazzez A, Moroney JR, et al: Laparoscopic vs open appendectomy in obese patients: Outcomes using the American College of Surgeons National Surgical Quality Improvement Program database. $J$ Am Coll Surg 2012; 215(1): 88-99.

26- Thereaux J, Veyrie, N. Corigliano N, et al: Is laparoscopy a safe approach for diffuse appendicular peritonitis? Feasibility and determination of risk factors for postoperative, intra-abdominal abscess. Surg Endosc 2014; 28: 1908-1913.

27- WeiHongbo Wei HB, Huang JL, Zheng ZH, et al; Laparoscopic versus open appendectomy:
A prospective randomized comparison. Surg Endosc 2010, 24: 266-269.

28- Yau, KK, Siu, WT, Tang CN, et al: Laparoscopic versus open appendectomy for complicated appendicitis. J Am Coll Surg 2007; 205: 60-65.

29- Brügger L, Rosella L, Candinas D, et al: Improving outcomes after laparoscopic appendectomy: A population-based, 12-year trend analysis 7446 patients. Ann Surg 2011; 253(2): 309-213.

30- Al-Mulhim AS, Al-Mulhim FM, AlSuwaiygh AA, et al: Laparoscopic versus open appendectomy in females with a clinical diagnosis of appendicitis. Saudi Med $J$ 2002; 23: 1339-1342.

31- Garst GC, Moore EE, Banerjee MN, et al: Acute appendicitis: A disease severity score for the acute care surgeon. $J$ Trauma Acute Care Surg 2013; 74(1): 32-36.

32- Frutos MD, Abrisqueta J, lujan J, et al: Randomized prospective study comparing laparoscopic appendectomy versus umbilical single incision appendectomy. Ann Surg 2013; 257(3): 413-418.

33- Vettoretto N, Gobbi S, Corradi A, et al: Consensus conference on laparoscopic appendectomy: Development of guidelines. Colorectal Dis 2011; 13(7): 748-754.

34- Wu HS, Lai HW, Kuo SJ, et al: Competitive edge of laparoscopic appendectomy versus open appendectomy: A subgroup comparison analysis. J Laparoendosc Adv Surg Tech 2011; 21(3): 197-202.

35- Gamal AK, Mohammad FA, Khalid RM, et al: Post appendectomy small bowel obstruction. Saudi Med J 2005; 26(7): 1058-1060 . 